\title{
China's Mobile Terminal Education: the Current Situation Based on Questionnaire Survey
}

\author{
Sun Yexia ${ }^{1}$, Li Jing ${ }^{1}$ \\ ${ }^{1}$ Northeast Normal University, People Street No. 5268, Changchun, Jilin Province, China.
}

Keywords: Mobile terminal education, talent education, questionnaire survey

\begin{abstract}
China's mobile terminal education becomes an important mode of talent education. The APP is the most popular due to the popularization of mobile phones and the development of Chinese mobile phone consumption habits. In order to demonstrate the current status of China's mobile terminal education APP, different questionnaires were designed for students of different levels. This paper conducted a questionnaire survey through the network and collected a large amount of sample data. The results show the details of Chinese current situation of China's mobile terminal education APP, such as the using time, the types of the APP and so on.

Quality education needs to pay attention to talent education. Talent education can enrich people's inner world, cultivate people's sentiments, and enhance personal taste. Even research is considered to be beneficial to intellectual development. Most families attach importance to talent education, taking into account the cultivation of children's comprehensive quality; some families feel that this is a "shortcut" for reading famous schools. Due to the popular use of mobile phones and the development of Chinese mobile phone consumption habits, mobile terminal talent education APP has become an important mode of talent education.
\end{abstract}

\section{The Preparation before the Survey}

\subsection{The purpose of the survey}

This survey focuses on the prospects of APP in talent cultivation, concentrates on users' understandings and attitudes towards talent APP, and aims to design a suitable talent education APP for different groups of people.

\subsection{Survey process}

The survey time was from November 10th, 2017 to December 30th, 2017. From November 10th to the end of November, various types of education APPs were experienced in the early stage, and group discussion and division of labor were conducted. From December 1st to December 10th, the questionnaires were designed and repeatedly amended after commissioning. From December 11st to December 15th, the launching and recycling of the questionnaires were completed by means of online answering and offline issuing by the team members. From December 15th to December 25th, the recycled questionnaires were sorted out and entered into the computer, and the recycled questionnaires data were processed by the statistical software SPSS and EXCEL. From December 15th to December 31st, a survey report was written. From January 1st, 2018 to January 10th, 2018, the survey report was re-examined and corrected.

The questionnaires included two types of respondents who were the students' parents of the primary school and below and the students of junior middle school and above. The survey methods of the questionnaires were both online and offline. What's more, the questionnaires were distributed to 23 cities in China, mainly in Jilin Province. Among them, 1,800 valid questionnaires for the students' parents of primary and below were taken back, and 2,424 valid questionnaires for the students of junior middle school and above were taken back.

\subsection{Methodology}

Survey methods: focus group discussion method, questionnaire method.

Data analysis tools: SPSS software, EXCEL software. 


\section{Questionnaire Analysis of the Students' Parents of Primary School and Below}

A total of 1814 questionnaires for the students' parents of primary and below were taken back, in which there were 1800 valid questionnaires. The survey involved first-tier cities, second-tier cities, thirdtier cities as well as fourth-tier cities at city-level and county-level. The ratio of male-female in students' parents was 37:63. The parents those who filled out the questionnaires in the parents group were mainly female parents. Some male parents refused to fill out the questionnaires because they did not understand them or the wives were in charge of them. This required that the interface and usage of the APP should not only be applicable to primary school students and below, but also took into account the preferences of female parents. Among the respondents, the proportion of the aged 25 and above accounted for 5\%, the aged 26-35 accounted for $60.33 \%$, the aged 36-45 accounted for $29.33 \%$, the aged $46-55$ accounted for $3.67 \%$, and the aged 56 and above accounted for $1.67 \%$. In the survey, $76 \%$ of the respondents had one child, $18.33 \%$ had two children, $0.67 \%$ had three or more children, and $5 \%$ had no children. In terms of the distribution of children's age, in addition to $5 \%$ of the respondents had no children, $25 \%$ were 3 years old and below, $21.33 \%$ were $4-6$ years old, $37.33 \%$ were $7-13$ years old, and $11.33 \%$ were 13 years old or above.

The monthly income of the surveyed families was relatively evenly distributed. $18.67 \%$ of the families were below 3000 Yuan (including 3000 Yuan), the proportion of 3001-5000 Yuan is 18\%, the proportion of 5001-10000 Yuan is 27\%, and those who had 10001-20000 Yuan accounted for $22.67 \%$.

The mobile terminal (mobile phones or iPads) system used by most of the respondents was apple system (44.33\%) or android system (42.67\%), and a small number of people had dual systems.

Except that $20.67 \%$ of parents did not allow their children to use mobile terminals (mobile phones or iPads), the time when children use mobile terminals is mainly after $5 \mathrm{pm}$.

The main way to train children in talent education was to find institutions or teachers, and $69.33 \%$ of the parents adopted this way.

$54.67 \%$ of the parents were willing to use relevant types of APPs (mobile phone software) for their children's talent education, those who were unwilling to use accounted for $31.67 \%$, and the proportion of those who held the indifferent attitude was $13.67 \%$.

If the talent education APPs (mobile phone software) were used, parents were more inclined to give children a wide range of courses, including musical instruments, dance, vocal music, calligraphy and painting, chess, sport and so on. Among them, the most popular courses were calligraphy and painting (35\%), musical instruments (34\%) and dance (29\%), and the folk art classes $(2.33 \%)$ were the most unpopular talents.

Most of the parents and children had been accustomed to the arrangement of offline courses. $44.67 \%$ of the parents could accept 30-60 minutes courses, 28.67\% could accept 15-30 minutes courses, 19\% could accept 1-2 hours, and 5.67\% could accept just less than 15 minutes.

Parents still preferred the combination of online teaching and offline experience, those who tended to this kind of teaching method accounted for $59.67 \%$, those who liked live courses were $18.67 \%$, those who were fond of recording courses occupied 9.33\%, and those who enjoyed providing offline education resources accounted for $12.33 \%$.

There were also many effects that parents wanted to reach by cultivating their children's talents and skills. Among them, $62.67 \%$ of parents wanted to mold their children's characters, $56 \%$ of them tried to develop their children's intelligences, and $47.67 \%$ of them attempted to educate their children's cognitive abilities.

For the children's talent education, parents need to invest in the children's talent education every month. $60.33 \%$ of the parents could accept to spend less than 500 Yuan on APP (mobile phone software), and even some parents paid much lower than 500 Yuan. In addition, 24\% of the parents were willing to spend 500-1000 Yuan.

When parents chose a talent education APP (mobile phone software), they paid more attention to the price, the scientific and reasonable courses arrangements, word-of-mouth evaluations, page designs, usage experience, large downloads, advertising propaganda, children's opinions, offline downloads, more 
discounts, good after-sale service and so on, in which the reasonable courses arrangements (55\%), children's opinions (51.67\%) and word-of-mouth evaluations (46\%) were especially highlighted by parents. The other options included the teachers' level, feedback and update strength, which were also valued by some parents.

There were many ways to learn about talent education APP (mobile phone software), but up to $84 \%$ of the parents chose an APP only through the introduction of friends, school teachers and so on. The next way was that the talent education APP was acquainted through the Internet and other online media advertisements.

Table 1 How to Know the Mobile Terminal Education APP

\begin{tabular}{|c|c|}
\hline $\begin{array}{c}\text { Introduced by friends, school teachers, } \\
\text { etc. }\end{array}$ & $84 \%$ \\
\hline Outdoor flysheet, etc. & $15.33 \%$ \\
\hline $\begin{array}{l}\text { Internet and other online media } \\
\text { advertisements }\end{array}$ & $\square$ \\
\hline $\mathrm{TV}$, radio, etc. & $16 \%$ \\
\hline Social media advertisements & $15.67 \%$ \\
\hline Other (please specify) & $1.33 \%$ \\
\hline
\end{tabular}

After using the APP for a period of time, some customers would delete an APP (mobile phone software) that was being used. The most important reason for deletion was that the APP was of poor quality (80\%), pop-up advertisement (60\%) and unstable performance (51\%).

The setting of the open-ended question about the expectations of the talent education APP has given us a lot of information. Among them, the proportion of the parents who filled out "no" or "nothing" accounted for 19\%. Many parents put forward specific requirements that the interface should be aesthetic and the children can easily identify it, and the system could be operated easily with powerful function. From the technology, it was required that the APP should not occupy much space with stable platform and less advertisements. From the price, it was required that the APP should be cost low with high price performance. In addition, it is expected that the course time should not be too long, and one-on-one teaching should be set up on account of teaching students in accordance with their aptitude. 5.3\% of the parents directly wrote the requirement of practical applicability, and there were some other parents having expressed the meaning of practical applicability. In terms of content, parents had made some suggestions that the courses should be taught with edutainment, the contents should be diversified, new and distinctive, and new things could be timely introduced. At the same time, they hoped that user experience could be enhanced, quality and quantity requirements could be fulfilled, the teachers' level would be guaranteed, famous teachers could be invited to participate in the class, teacher-student interaction part could be designed, and some non-profit courses could be shared with students. Furthermore, it was expected that the training effect would be the same as that of the actual teacher, and meanwhile, parents hoped that there would be much lower price for the courses.

\section{Questionnaire Analysis of the Students of Junior Middle School and Above}

In the third currently on-going upgrading of consumption structure, the fastest growth is the consumption in education. For junior middle school students and above, they have the right to choose the APP. The survey of this group is mainly for the students themselves. A total of 2430 questionnaires for the students of junior middle school and above were taken back from online and offline, in which there were 2424 valid questionnaires. The ratio of male-female in the respondents was 47.65:52.35. The study period included junior middle school, senior high school or technical secondary school, junior college, undergraduate, postgraduate and above. Among them, the proportion of the students who were in postgraduate stage was $25.99 \%$, the proportion of the students who were in undergraduate stage was $24.75 \%$, the proportion of the students who were in junior college was $18.81 \%$, the proportion of the 
students who were in senior high school or technical secondary school was $16.09 \%$, and the proportion of the students who were in junior middle school was $14.36 \%$.

The proportion of the students with mobile terminals (mobile phones or iPads) was up to 97.57\%, and only a tiny minority of students did not have mobile terminals. The mobile terminal system used by most of the students was mainly android system, accounting for $57.67 \%$, and the proportion of those were using apple system was $33.54 \%$, meanwhile, there were also $8.54 \%$ of the respondents had dual systems.

The proportion of the students who used mobile terminal equipment everyday was up to $82.99 \%$, the proportion of the students who used 1-3 days a week was 6.25\%, and those who used 4-6 days a week accounted for $10.76 \%$. The maximum mobile phone users were those who used mobile phones after 7:30 $\mathrm{pm}$, with a proportion of $76.74 \%$. There were $45.17 \%$ of the students using mobile phones during the lunch break that was from 11:30 to 13:30, and those who used mobile phones before 8:00 were the least, still with a proportion of $20.54 \%$.

Table 2 The Time Interval to Use the Mobile Terminal

\begin{tabular}{|c|c|}
\hline Before 8:00 & $\square \quad 20.54 \%$ \\
\hline 8:00-11:30 & \begin{tabular}{l|l} 
& $34.78 \%$
\end{tabular} \\
\hline 11:30_-13:30 & E \\
\hline $13: 30-17: 00$ & $30.82 \%$ \\
\hline 17:00-19:30 & 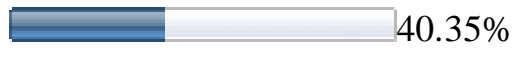 \\
\hline After 19:30 & $\begin{array}{ll} & 76.74 \%\end{array}$ \\
\hline
\end{tabular}

The software that commonly used by survey respondents covered photography, learning, games, social interaction, shopping, reading, audio and video, and so on. Among them, the social interaction accounted for $76.61 \%$, the shopping accounted for $59.16 \%$, the audio and video was $56.68 \%$, the photography was $55.20 \%$, and the learning software was $49.63 \%$. At the same time, the answers filled in the other column were all included in the learning category.

In addition to $10.64 \%$ of the respondents who did not learn talent, there were various choices for other respondents. Among them, the number of the students who chose to study in the tutorial class was $30.69 \%$, the proportion of those who learned by one-to-one education was $22.52 \%$, those who used talent education APP accounted for $14.36 \%$, those who used computer network courses occupied $21.04 \%$, and those who studied by themselves were $38.99 \%$. The use of talent education APP was in the least proportion, but those who utilized computer network courses were the most potential customers of talent education APP. The reasons for choosing self-study were various, some students were to learn much faster and more suitable for their own pace, some students were considering that the organization was too far away, and some thought that it was too expensive to learn from the home tutor. While, the talent education APP could solve these problems and gain more customers.

The talents and skills that were prepared to be learned or were being learned were relatively scattered, which included musical instruments $(41.71 \%)$, dance $(24.01 \%)$, vocal music $(14.98 \%)$, calligraphy and painting (22.90\%), chess (9.9\%), sports (25.87\%), performance $(10.27 \%)$, handmade puzzle $(11.01 \%)$, and opera (3.71\%). The proportion of the respondents who neither studied nor planned to study the talents and skills was $9.53 \%$. Among the talents and skills, the most popular ones were musical instruments, sports and dance, and opera was still the most unpopular one.

Accustomed to the traditional teaching method, the respondents still preferred the combination of online teaching and offline experience, those who tended to this kind of teaching method accounted for $59.78 \%$, those who liked live courses were $20.92 \%$, those who were fond of recording courses occupied $16.34 \%$, and those who enjoyed providing offline education resources accounted for $26.24 \%$.

There were also many effects that the students wanted to reach by cultivating their own talents and skills. Among them, $62.5 \%$ of the students wanted to mold characters, and $59.41 \%$ of them hoped to enrich their after-school lives. Other purposes of learning talents and skills included social interaction 
(30.45\%), physical fitness (30.07\%), professional training (29.33\%), and performance requirement $(11.88 \%)$.

The estimated expenditure of the students was relatively small. For their talent education, 66.96\% of the students could accept to spend less than 100 Yuan on APP (mobile phone software), 21.04\% of them were willing to spend 101-500 Yuan, and only 7.05\% were willing to spend 500-1000 Yuan.

When the students chose a talent education APP, the word-of-mouth evaluations $(55.32 \%)$ and the experience (50.37\%) were especially highlighted, followed by the scientific and reasonable curriculum (44.93\%) and price (44.43\%). In addition, page designs, friend recommendations, large download, advertising propaganda, offline downloads, and discounts were also settled on.

There were many ways to learn about talent education APP (mobile phone software), but up to 68.94\% of the students chose an APP only through the recommendation of friends, school teachers and so on. The next way was that the talent education APP was acquainted through the advertisements of online push (36.26\%), online media (31.31\%) and social media (32.55\%). Furthermore, the advertisements of televisions, radios, outdoors, and leaflets were also ways to know about talent education APP.

After using the APP for a period of time, some customers would delete an APP (mobile phone software) that was being used. The most important reason for deletion was that the APP was of boring contents (71.78\%), occupying the memory (70.05\%), and no features (46.41\%). In addition, high cost (39.98\%), affected academics (28.34\%), poor updates (25.74\%), bad after-sales services (23.51\%), and poor responsive environments (22.65\%) were also reasons for deleting an APP that was being used.

The last open-ended question about the expectations of the talent education APP has given us a lot of information. Apart from the fact that $9.47 \%$ of the students did not fill out or filled in the invalid information, other students put forward many specific requirements on functions, forms and contents of talent education APP. From the functions, it was required that the APP should have good conformability, strong usability, friendly interface, off-line usage, multiple functions, no taking up much space, no advertising insertion, and shareable resource. From the forms, it was expected that the courses could be cost low with high price performance, and the APP should have the forms of online-offline combination, good teacher-student interaction, free courses, scientific teaching methods, and vigorous user experience. From the contents, it was hoped that the APP had novel, practical and useful contents, personalized teaching, appropriate edutainment, good amusement, and timely update.

\section{Conclusion}

Talent education is currently demanding for the young and the university students. In the future, the proportion of talent education will continue to increase to have a share of the basic education market. In China, more and younger people study through the APP. At present, there is a forward-looking market for talent education APP. In addition, the detailed data information provides suggestions for the design of China's mobile terminal education APP, which can further clarify APP curriculum design, teachers and APP peripheral products.

\section{Reference}

[1]. Hou Dianmu, Social Survey Research Methods, Peking University Press, 2014.

[2]. Cai Jinmei, The Survey and Prospects of the Status Quo of China's Basic Network Education, Basic Education, 2012 (8).

[3]. Hua Yan, Tong Xiaohong, Investigation and Research on Mobile Learning Status of Network Education, Journal of Anhui Radio and TV University, 2016(4). 